\title{
Healthcare Providers' Perceptions of the Sexual and Reproductive Health Needs (Including Family Planning) of Elderly Women from Selected Sites in Botswana
}

\author{
Njoku Ola Ama ${ }^{1}$, Enock Ngome ${ }^{2}$ \\ ${ }^{1}$ Department of Statistics, University of Botswana, Gaborone, Botswana; ${ }^{2}$ Department of Population Studies, University of Botswana, \\ Gaborone, Botswana. \\ Email: amano@mopipi.ub.bw,njoku52@gmail.com, enock.ngome@gmail.com
}

Received May $3^{\text {rd }}$, 2012; revised June 28 ${ }^{\text {th }}$, 2012; accepted July $7^{\text {th }}, 2012$

\begin{abstract}
Much of the sexual and reproductive health services and service delivery including family planning target women of child bearing ages (15 - 49 years) and sometimes men. Hardly are there programmes/interventions that specifically target the needs of the elderly women (50 years and above), yet this group has serious sexual and reproductive health needs as many of them are still sexually active. This cross-sectional study obtained the views of a stratified random sample of 169 healthcare providers (doctors, nurses and pharmacists) from four selected sites, Gaborone, Selibe Phikwe, Barolong and Kweneng East health districts in Botswana on how the healthcare system in the selected sites is meeting the SRH/FP needs of the elderly women. The study found out that while overwhelming majority of the healthcare providers feltthat the healthcare system has no programme that specifically target the SRH/FP needs of this significant others and their SRH/FP needs are not being met, less than 15\% indicated that Pap smear screening as well as screening of cervical cancer were on-going. Although there are SRH/FP services available in the healthcare system, the elderly women are minimally accessing these services. Only condom, combined oral contraceptives, progestogen-only pills, treatment of STIs, screening for HIV/AIDS and screening for cervical cancer are accessed and information is also limited to these services. Reasons given by the healthcare providers for the non-accessibility of these services were cultural diversity (80\%), people's sexual behavior and perceptions about sex (79\%), lack of knowledge about the desired SRH/FP services (76\%), religion (73\%) and gender issues (62\%). The study, advocates as part of policy options to mitigate the obstacles to accessing SRH/FP services, the expansion of counseling programmes, screening and treatment for breast cancer, public awareness campaigns, production and circulation of appropriate educational materials, effective training of healthcare providers and the establishment of separate clinic days for the elderly women' SRH/FP services.
\end{abstract}

Keywords: Healthcare Providers; Elderly Women; Sexual and Reproductive Health Services; Family Planning

\section{Introduction}

Goal 5b of the Millennium Development Goals (MDGs), emphasizes the universal access to reproductive health (RH), including FP services. Yet, much of the sexual and reproductive health (SRH) services and service delivery including family planning (FP) target the women of child bearing ages (15 - 49 years) and sometimes men. Hardly are there special programmes/interventions that specifically target the needs of the elderly women (50 years and above), including the vulnerable ones in this age group. This group has serious sexual and reproductive health needs. They suffer from lifelong effects of sexual bias and low social status which can be burdensome. They bear emotional and economic burdens which are associated with their responsibility as family caregivers, look- ing after ageing parents, older husbands, orphans or abandoned grandchildren [1]. The elderly women's role in a country such Botswana is critical as they play significant roles in the families as caregivers in this era of HIV/AIDS. An understanding of the challenges they face in accessing their SRH needs including family planning through the perspectives of the healthcare providers is crucial to development and implementation of public health intervention programmes that will address these challenges and enable them have quality life. It is also known that well over half the women over age 60 live in developing countries [2,3].

The key primary healthcare providers in Botswana are the doctors, nurses and pharmacists who are employed in the hospitals and clinics throughout the country. They are conversant with the facilities and infrastructure for the 
provision of healthcare to the inhabitants of the country, including patients who make use of these facilities. The perceptions of these healthcare providers reflect the true reproductive health attitudes of the elderly women and the extent of availability and accessibility of these services to them. In addition, the opinions of the healthcare providers can help inform policies aimed at improving healthcare delivery in Botswana.

Healthcare providers provide screening and treatment of gynaecological disorders including reproductive and urinary tract infections, uterine prolapse, and fistulas. The screening and treatment of precancerous cervical lesions is a clear need in many developing countries, particularly in sub-Saharan Africa, Latin America, and South Asia [4]. The screening for breast cancer and treatment is also important for the good health of the elderly women. As most of the elderly women in Botswana are involved in caregiving for orphaned, destitute children or family members living with HIV and AIDS, it is important to institute medical management, particularly for those women at high risk of fractures and cardiovascular disease [5].

The proportion of elderly people who remain sexually active varies considerably with age, sex, marital status and general health. Estimates indicate that about $55 \%$ of married women over 60 years and up to $24 \%$ of married women over 76 years are sexually active [6]. In Australia, $12.4 \%$ of the population in 2001 was aged over 65 years, a proportion that is projected to rise to $21.3 \%$ by 2031 [7]. Studies in developing countries have shown that women go through gynecological problems throughout their reproductive years and beyond, in part due to the limited medical care they receive during labour and delivery, combined with high parity [8,9]. As they move towards menopause and beyond, they are at risk from symptoms associated with hormonal changes, heart disease, gynecological malignancies and various genitourinary conditions $[1,10]$. Their health at this time depends to a large extent on the state of their health before menopause. They can still be pregnant as most of them are still sexually active, although pregnancy at this time is usually neither desired nor desirable.

Sexual and reproductive health (SRH) services including family planning services that protect the elderly women from unwanted pregnancies, especially with short intervals, and sexually transmitted diseases (STIs) add very much on how well their premenopausal and postmenopausal health will be. The women need the protection that condoms provide against sexually transmitted diseases including HIV/AIDS. As women reach menopause they need help to manage symptoms. After menopause, women face new long term health risks, including hormonal changes that contribute to an increased risk of cardiovascular disease and osteoporosis and which contribute to reduced sexual desires [11].

Despite the clear need to focus resources on women of reproductive age, the public health services also need to ensure that the health needs of older women, including their sexual and reproductive health needs, are adequately addressed. [10] revealed that about $31.4 \%$ of postmenopausal women suffered from obstetric-related gynecological diseases. In most cases there is hardly information on the SRH needs of the elderly women. For instance, in Sri Lanka, the routine MCH/FP information system of the Ministry of Health, Sri Lanka monitored by the Family Health Bureau at present, do not collect data with special reference to elderly women. The Sri Lanka Demographic and Health Survey 2000 only collected information on fertility, family planning and other selected reproductive health issues of the ever-married women aged 15 - 49 years. Researchers, therefore, rely mostly on clinical impressions and experiences about the elderly women's health profile [12].

Botswana has made significant progress economically since independence in 1966. She has relatively good roads, solid communications network, and 24-hour hospitals that are fairly well distributed throughout the country, yet Botswana has serious barriers to comprehensive sexual and reproductive health care including family planning [13]. While the government requires that sexual and reproductive health (SRH) services, including family planning, prenatal care, delivery, post-abortion care, and STI services are provided at no cost by maternity care providers, hospitals and government clinics, indicators such as maternal mortality, feminization of HIV, and contraceptive prevalence do not reflect a system that meets the needs of its population [13]. Contraceptive prevalence in Botswana still remains at $48 \%$ [14].

About $90 \%$ of people in Botswana are known to live within 15 kilometers of a health centre, yet use of these centers for SRH services is very low, especially among young people. The availability of sexual and reproductive health services do not necessarily translate to accessibility, particularly for young people. The young people indicate that they are kept away by inconvenient hours, poor information about services, and unwelcoming attitudes toward youth among service providers [15]. The elderly women might be going through the same experiences as the young people. There are no literature so far on programmes or interventions targeting the elderly women or are there data on elderly women's sexual and reproductive healthcare including family planning. There are relatively limited information on the physical, psychological and social problems of the elderly women. The women themselves hardly seek care, often because they accept their physical discomfort associated with gy- 
necological problems, menopause, and ageing as natural $[9,16]$. A study in Botswana on older population and health system (the case of chronic disease-hypertension) showed that $48 \%$ of the elderly could not access healthcare because they were far. Transport availability was also raised as an issue as $62 \%$ of them said they walked [17] (Older Population and Health System: A profile of Botswana).

This study documented the views of the healthcare providers, from the selected sites for the study, on the perceived sexual and reproductive health needs (including family planning services) of elderly women, availability and accessibility of sexual and reproductive healthcare services (including family planning services), sources of information for SRH/FP needs, factors which influenced the accessibility of reproductive health services to the elderly women, interventions and policy changes to improve access to SRH/FP needs of the elderly women. The availability of sexual and reproductive health services in this study was measured by the physical presence of the desired services and the presence of qualified, nondiscriminatory healthcare providers at the service points. This information from this study will be necessary for policy makers, the government of Botswana and the private sector to shape intervention measures to assist elderly women to seek and access the desired sexual and reproductive health services.

This paper follows from a larger study between February and October, 2011 [18] and relies on information provided by the sampled healthcare providers serving in hospitals and clinics from the study sites.

\section{Methodology}

The main study from which this paper has emanated was a cross-sectional study conducted between February and October 2011 and was supported by funding from the Office of Research and Development, University of Botswana. The study was on sexual and reproductive health of elderly women from the following selected sites in Botswana: Gaborone, Selibe Phikwe (2 urban health districts), Kweneng East and Barolong (2 rural health districts). The selection of the districts for the study was informed by closeness to Gaborone (the capital of country) and to reduce cost of the study since it was a case study that could lead to a national study. The choice of equal number of urban and rural health districts was to assist comparison of urban and rural women's experiences on sexual and reproductive health issues.

[19] showed that for a population of 5657 healthcare providers in Botswana [20], a statistically adequate national sample size for the study is 360 healthcare providers. Sixty per cent of this statistically determined sample size $(n=216)$ was allocated to the four selected districts using probability proportional to size (PPS), where the size represents the population of healthcare providers working in each health district. This allocated number (n = 216) is about three and a half times the expected sample size that would have been allocated to the selected sites but this was done to ensure that enough information was collected to facilitate appropriate analysis and interpretation of the results. At the end of the studies, 169 healthcare providers (123 nurses, 40 medical doctors and six pharmacists) were successfully interviewed, giving a response rate of $78.2 \%$ which is very much higher than [21].

Only one instrument, questionnaire, was used for the study. Questionnaires were administered to the healthcare providers by trained research assistants, who explained the purpose of the study and obtained informed consent. The questionnaires were coded to ensure the anonymity of the respondents. Most questionnaires were completed in the presence of the research assistants, while some were completed by participants at a more convenient time (self-administered) and returned to the research assistants within one to three days. The questionnaire contained questions about the healthcare providers' demographic characteristics, their opinions on the reproductive health needs of the elderly women, availability and accessibility of reproductive health services to elderly women, sources of information on sexual and reproductive health services available in the public health system in Botswana and factors that influence the accessibility of these services to the elderly women. Some of the questions were open-ended so that the healthcare providers could further provide information to clarify their responses on the perceived experiences of the elderly women in accessing reproductive healthcare services, including family planning.

The questionnaire was reviewed by experts in public health and ageing for quality, clarity and content in addressing the objectives of the study. It was latter approved by the University of Botswana Institutional Review Board (IRB) and the Ministry of Health Research and Ethical Committee before being used. A two-day training workshop for the research assistants was organized and the contents of questionnaire were explained to them. Permission to conduct the study was also obtained from the District Health Management Teams in each of the selected health districts.

Data were captured using the Statistical Package for the Social Sciences (SPSS) computer programme. All variables, including the responses to the open-ended questions, were coded before being captured using the programme. Data were analyzed using descriptive measures, such as percentages, means, standard deviation, correlation analysis and inferential statistics, such as the 
t-test. The t-test was used to determine if there were significant differences in opinions of the doctors and nurses on the elderly women's accessibility and availability of SRH services, including family planning. Graphical representations helped to further illustrate the results obtained. The results of the study were disseminated through departmental seminars.

\section{Results}

\subsection{Demographic Characteristics of the Healthcare Providers}

The analysis of the data from the study shows that $55.6 \%$ $(\mathrm{n}=94)$ of the healthcare providers were female while $44.4 \%(\mathrm{n}=75)$ were male; $24.9 \%$ were between 20 and 29 years old, $33.7 \%$ between 30 and 39 years; $27.8 \%$, between 40 and 49 years and $13.6 \%$ were 50 years and over. More than half of the health care providers (55\%) had diploma certificate while $37.3 \%$ had university degree; $3.6 \%$ had attempted degree and $4.1 \%$ had professional certificate. A little over a half of them (52.7\%) were married while $40.8 \%$ were single (never married) and $6.5 \%$ were cohabiting, divorced or widowed. The sample was skewed towards nurses as an overwhelming majority $(72.8 \%)$ belonged to that professional class while $23.7 \%$ were medical doctors and $3.5 \%$ were pharmacist (Figure 1). This skewed distribution of the healthcare providers in the studied sample is reflective of the population of healthcare providers in Botswana where over $89 \%$ are nurses [20].

\subsection{Meeting the SRH/FP Needs of the Elderly Women}

The healthcare providers were asked to indicate whether in their opinions the SRH/FP needs of the elderly women were met from the hospitals and clinics in the selected sites. The responses which were classified as $1=$ Yes, $2=$ No, and 3 = Don't know, are shown in Figure 2. The figure shows that majority of the healthcare providers (42\%) said the needs are not met while $38 \%$ were on the affirmative. The percentages of medical doctors, nurses

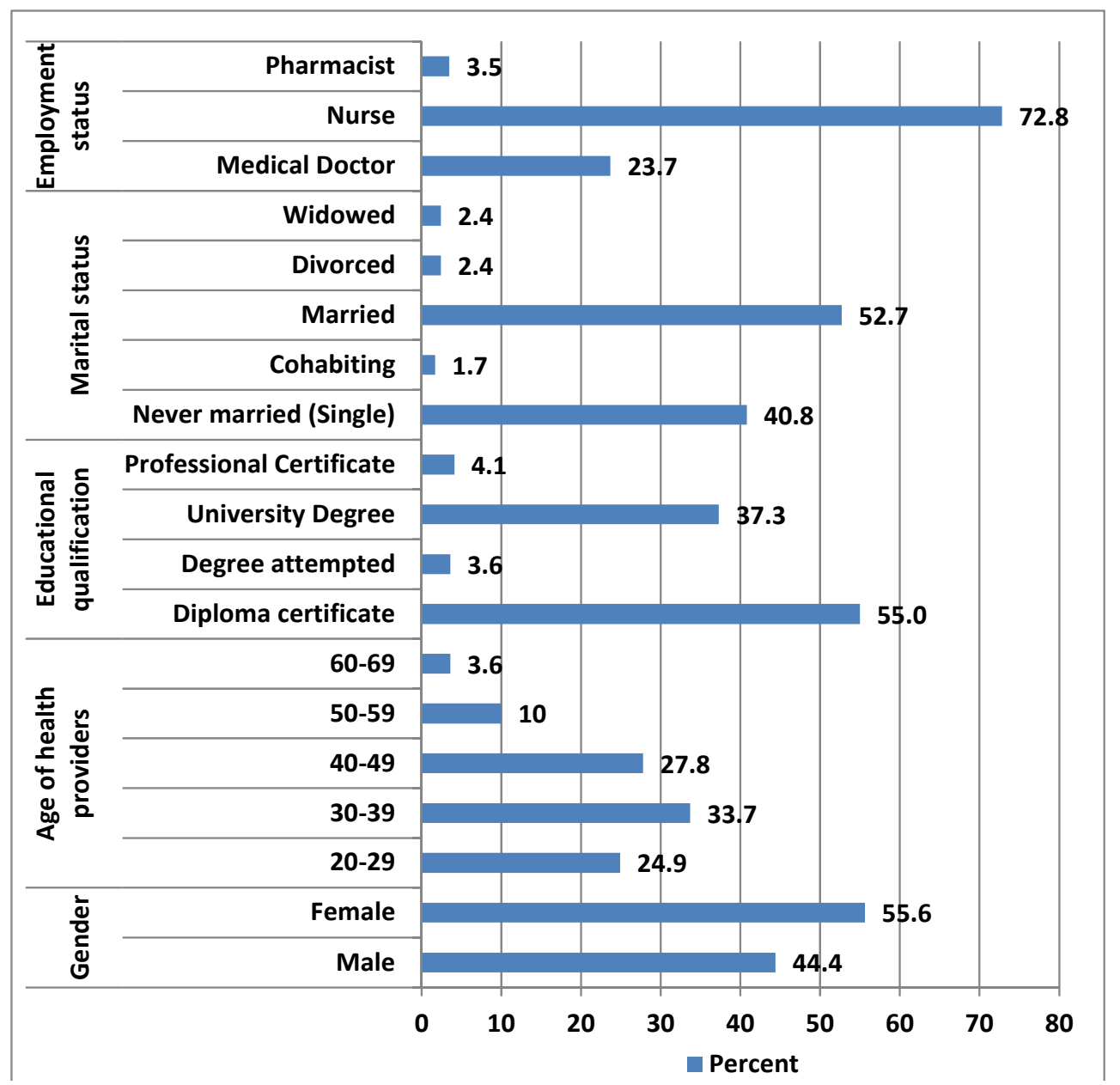

Figure 1. Demographic characteristics of the healthcare providers. 


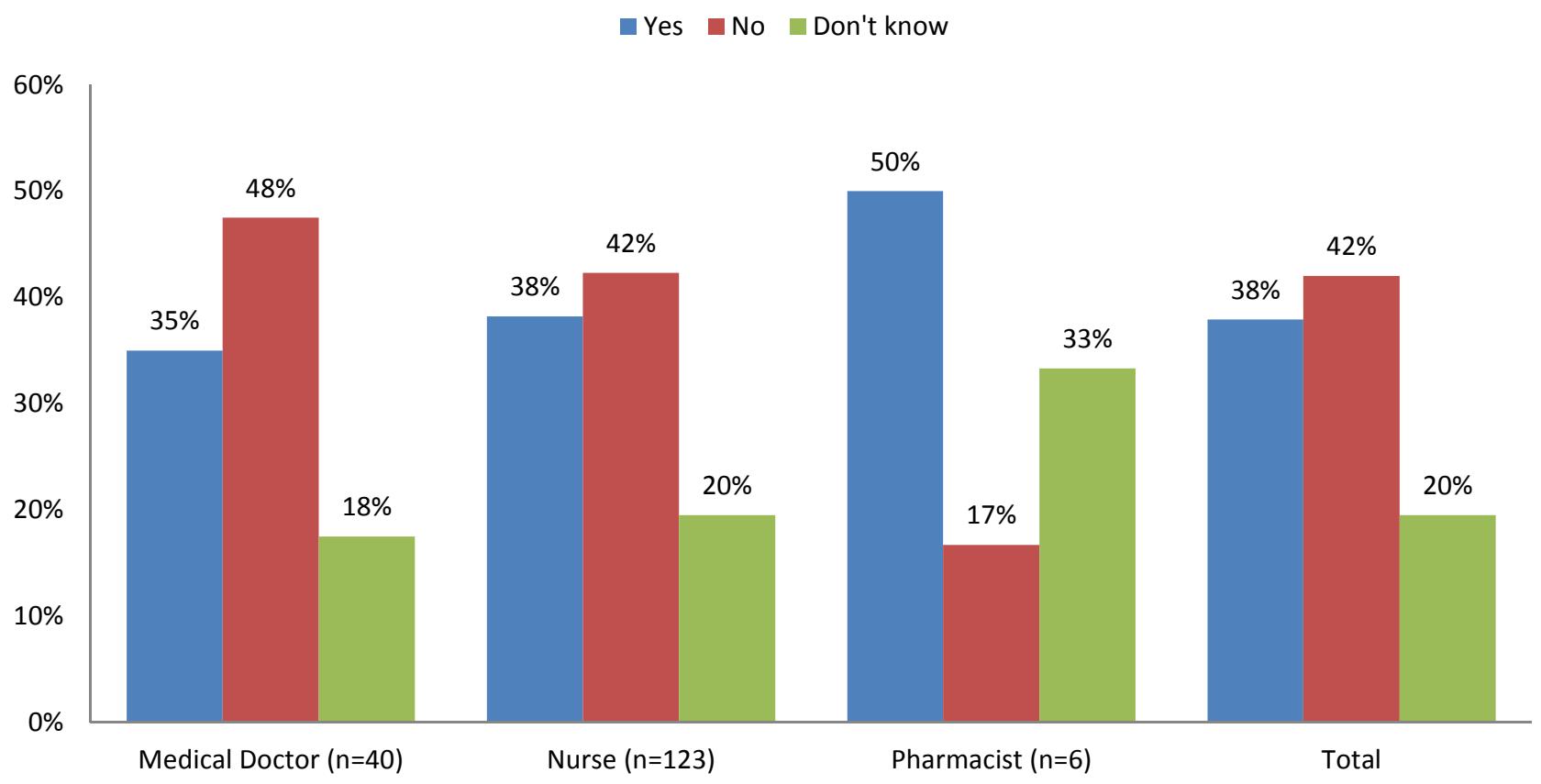

Figure 2. Healthcare providers' opinion on whether SRH/FP needs of elderly women are met.

and pharmacists that were in the affirmative were $35 \%$, $38 \%$ and $50 \%$, respectively, while $42 \%, 48 \%$ and $17 \%$ of the doctors, nurses and pharmacists, respectively said the needs are not being met.

\subsection{Programme Targeting SRH/FP Needs of the Elderly Women}

An open-ended question was posed to the healthcare providers to pinpoint any programme in Botswana public health system that targets the elderly women's sexual and reproductive health needs, including family planning. The results are displayed in Figure 3. The figure shows that all the pharmacists, $71 \%$ of the nurses and $67 \%$ of the medical doctors agree that there is no programme that specifically targets the SRH/FP needs of the elderly women in Botswana. However, $14 \%$ of the doctors and $9 \%$ of the nurses were of the view that Pap smear screening was on-going for the elderly women, as well as screening of cervical cancer (6\%, doctors; $5 \%$, nurses).

\subsection{Sexual and Reproductive Health/Family Planning Services Available in the Public Health System}

Although the study has shown that there are no specific programmes that target the SRH/FP needs of the elderly women, there are family planning services that any desiring elderly women can access. The healthcare providers were, therefore, asked to specify the sexual and reproductive health/family planning services that were available in the healthcare system. The results are shown in Table 1. Condom (all the doctors, 93\% of nurses and $80 \%$ of pharmacists), combined oral contraceptives (all the pharmacists, $89 \%$ of doctors and $84 \%$ of nurses), intrauterine device (IUD) (78\% of doctors, $75 \%$ of nurses and $20 \%$ of pharmacists) and progestogen-only pills (all the pharmacists, $72 \%$ of doctors and $65 \%$ of nurses) are the top four services that are available.

Treatment for STIs, screening for HIV/AIDS, screening for cervical cancer and prevention of mother-to-child transmission services (PMTCT) were the top four SRH services most available in the healthcare system. In addition to these, over $90 \%$ of the doctors also identified antenatal care services, screening for STIs and treatments for HIV/AIDS as being very much available in the healthcare system (Figure 4).

\subsection{Sexual and Reproductive Health/Family Planning Services Accessible to the Elderly Women}

When asked whether these services were accessible to the elderly women in the terms of proximity to the service points, cost of services and availability of qualified healthcare providers to administer these services, the healthcare providers enumerated those services that were accessible to the desiring elderly women. These are shown in Figure 5. Condom, combined oral contraceptives and progestogen-only pills were the top three services accessible to the elderly women. However, all the pharmacists acknowledged the accessibility of combined injectable contraceptives, barrier methods and emergency contraception. Breastfeeding was also highly rated by the nurses 


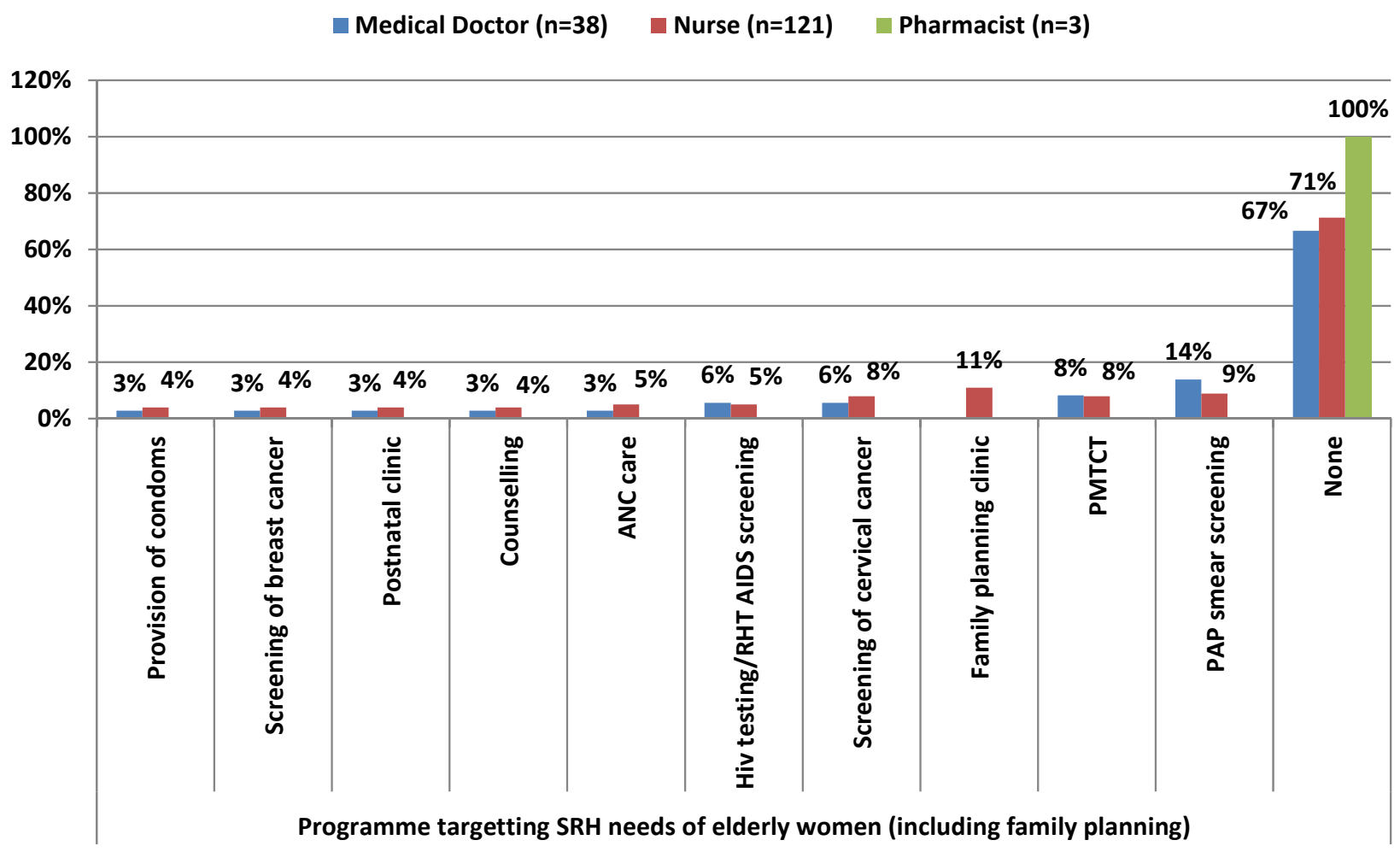

Figure 3. Identified programmes that target SRH/FP needs of elderly women.

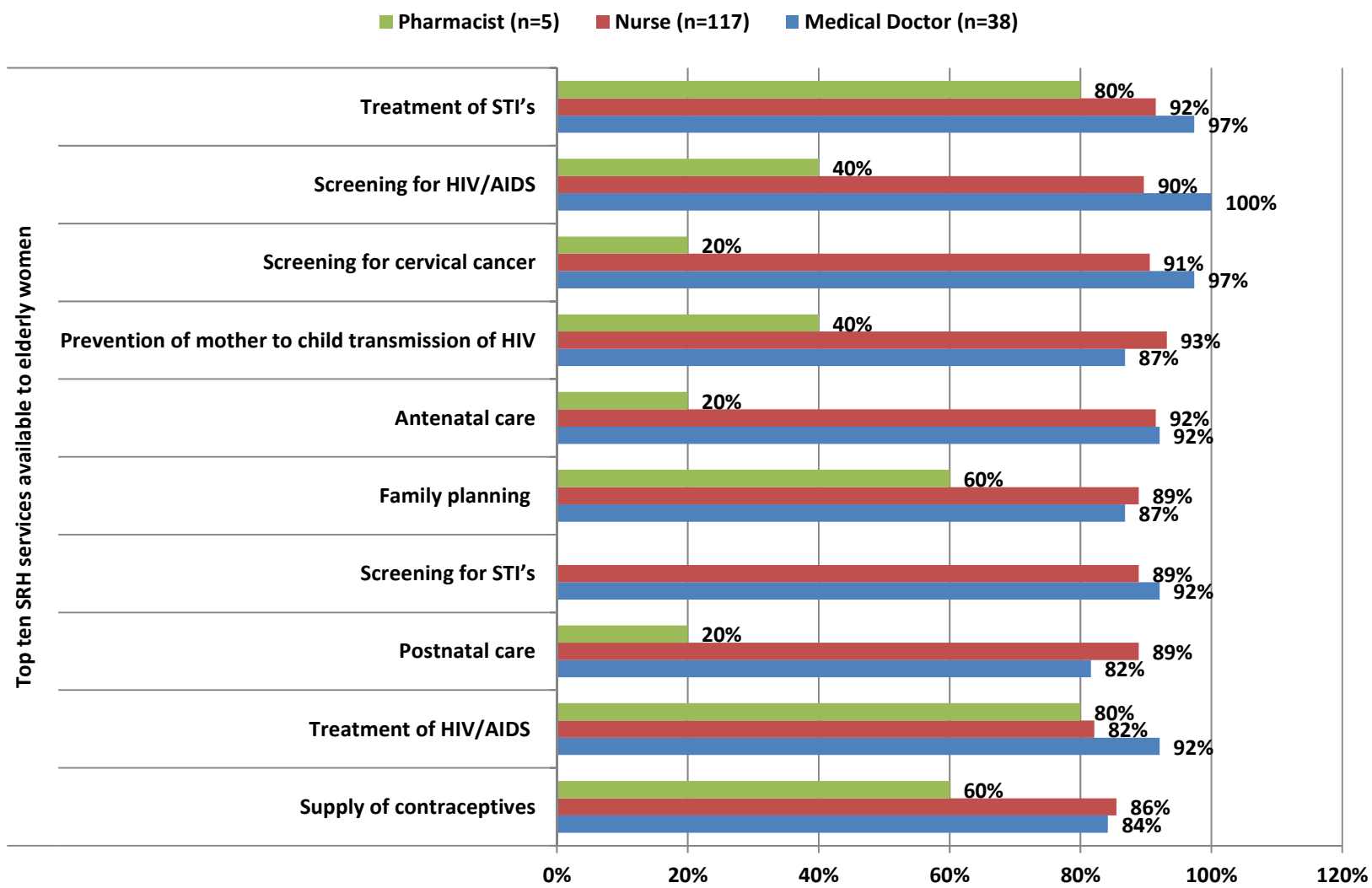

Figure 4. SRH services available in healthcare system in Botswana. 


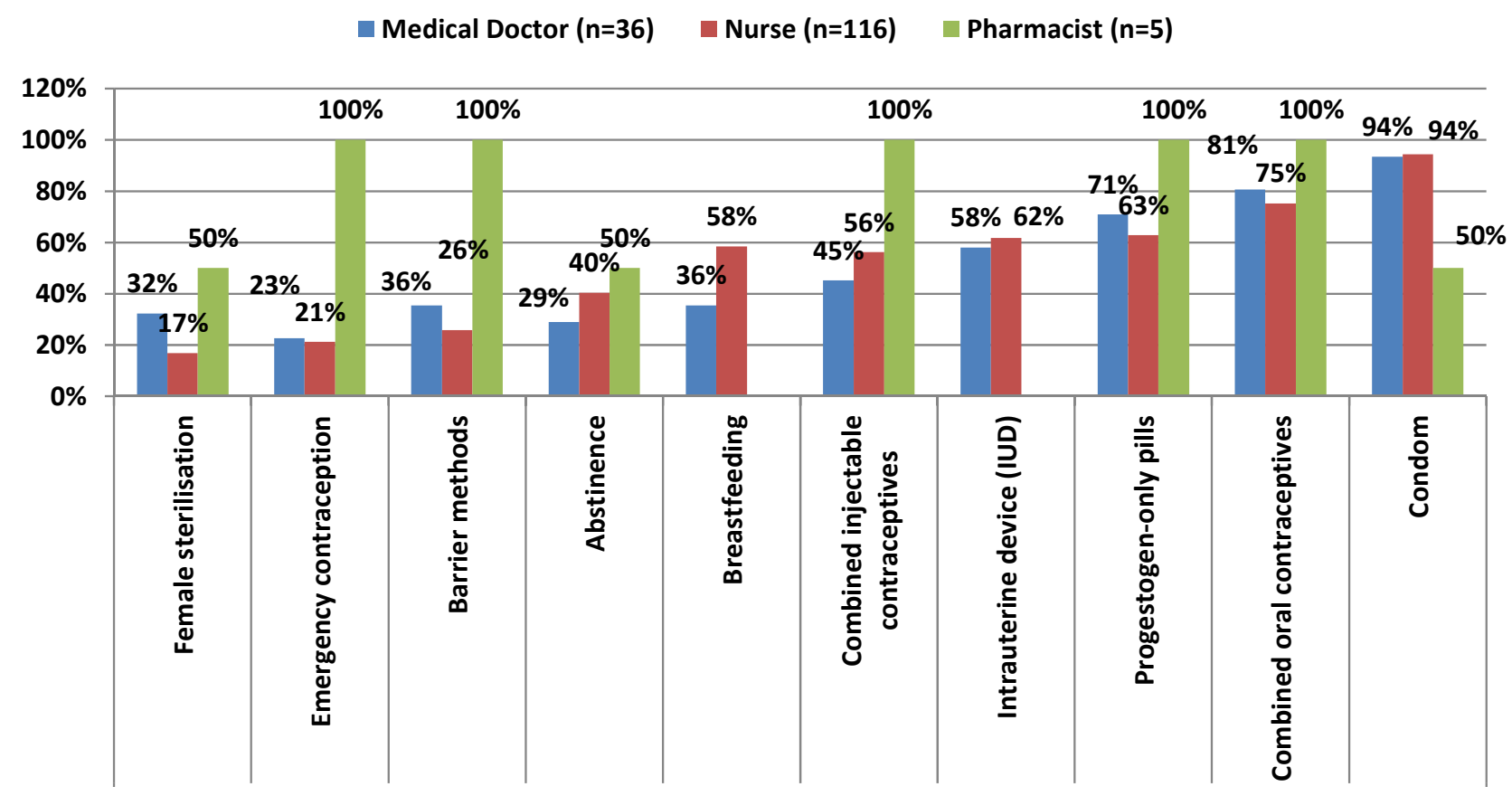

Figure 5. Top ten family planning services accessible to the elderly women.

Table 1. Opinion of healthcare providers on family planning services that are available in the healthcare system.

\begin{tabular}{|c|c|c|c|}
\hline Family planning services available & Medical doctor $(n=36)$ & Nurse $(n=116)$ & Pharmacist $(n=5)$ \\
\hline Condom & $100 \%$ & $93 \%$ & $80 \%$ \\
\hline Intrauterine device (IUD) & $78 \%$ & $75 \%$ & $20 \%$ \\
\hline Combined oral contraceptives & $89 \%$ & $84 \%$ & $100 \%$ \\
\hline Progestogen-only pills & $72 \%$ & $65 \%$ & $100 \%$ \\
\hline Combined injectable contraceptives & $53 \%$ & $65 \%$ & $80 \%$ \\
\hline Female sterilisation & $36 \%$ & $35 \%$ & $20 \%$ \\
\hline Breastfeeding & $42 \%$ & $66 \%$ & $0 \%$ \\
\hline Spermicides & $19 \%$ & $15 \%$ & $20 \%$ \\
\hline Barrier methods & $33 \%$ & $31 \%$ & $40 \%$ \\
\hline Sterilization & $44 \%$ & $22 \%$ & $0 \%$ \\
\hline Emergency contraception & $44 \%$ & $23 \%$ & $80 \%$ \\
\hline Diaphragm & $44 \%$ & $20 \%$ & $0 \%$ \\
\hline Vasectomy & $39 \%$ & $23 \%$ & $20 \%$ \\
\hline Norplant & $36 \%$ & $12 \%$ & $0 \%$ \\
\hline Abstinence & $44 \%$ & $62 \%$ & $80 \%$ \\
\hline Withdrawal & $25 \%$ & $35 \%$ & $60 \%$ \\
\hline Observation of safe periods & $36 \%$ & $38 \%$ & $20 \%$ \\
\hline
\end{tabular}


(58\%) in terms of accessibility to the elderly women.

The treatment for STIs, screening for HIV/AIDS and screening for cervical cancer were the top SRH services that were accessible to the elderly women. In addition, $90 \%$ of the doctors indicated that screening for STIs and treatment for HIV/AIDS were also very much accessible to the elderly women (Figure 6).

\subsection{Information Availability on the Accessible SRH/FP Services}

One of the strategies for increasing access to SRH/FP is the dissemination of information about sexual and reproductive health/family planning and available services. Public media can serve this function if the outreach is targeted toward marginalized and vulnerable populations [22]. Using radio as a tool for advocacy and awareness on reproductive and sexual health can also be another powerful tool. For example, the women's youth organization YWCA in Papua New Guinea has been a pioneer in using radio as a tool for advocacy and awareness on reproductive and sexual health. On the Tokstret Radio Project, a call-in program that provided a forum for discussion of reproductive and sexual health issues, women took the lead in talking about highly taboo issues related to sex and the use of male and female condoms. They were able to break down cultural barriers and paved the way for open discussions on reproductive health issues. The program also had a significant impact on men, who began calling in seeking advice on behalf of their wives [22,23].

The healthcare providers were asked to indicate if information on available SRH/FP services in the healthcare system were made available to the elderly women and in what forms. Figures 7, 8 and Table 2 show the family planning services, sexual and reproductive health services that the elderly women have information on, and the sources of those information, respectively.

Figure 7 reveals that information is mostly available on condom (91\% of doctors, $88 \%$ of nurses and $80 \%$ of pharmacists), combined oral contraceptives, progestogen-only pills, and breastfeeding.

Table 2 shows that information on sexual and reproductive health services are mostly available on the following: services for screening for HIV/AIDS, PMTCT, screening for cervical cancer and treatment for STIs. All the pharmacists strongly feel that information on supply of contraceptives and family planning are very much available.

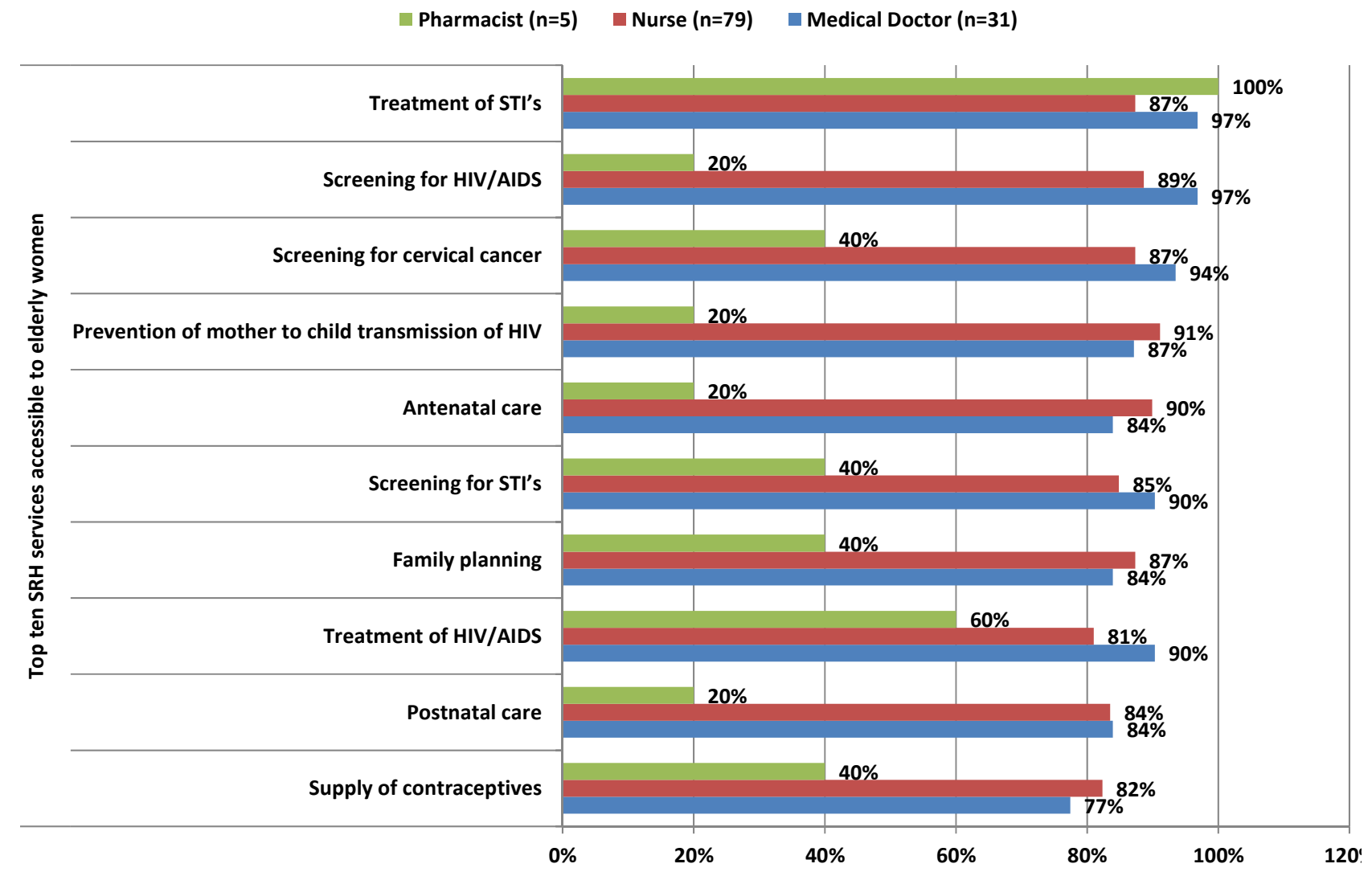

Figure 6. Sexual and reproductive services accessible to the elderly women. 


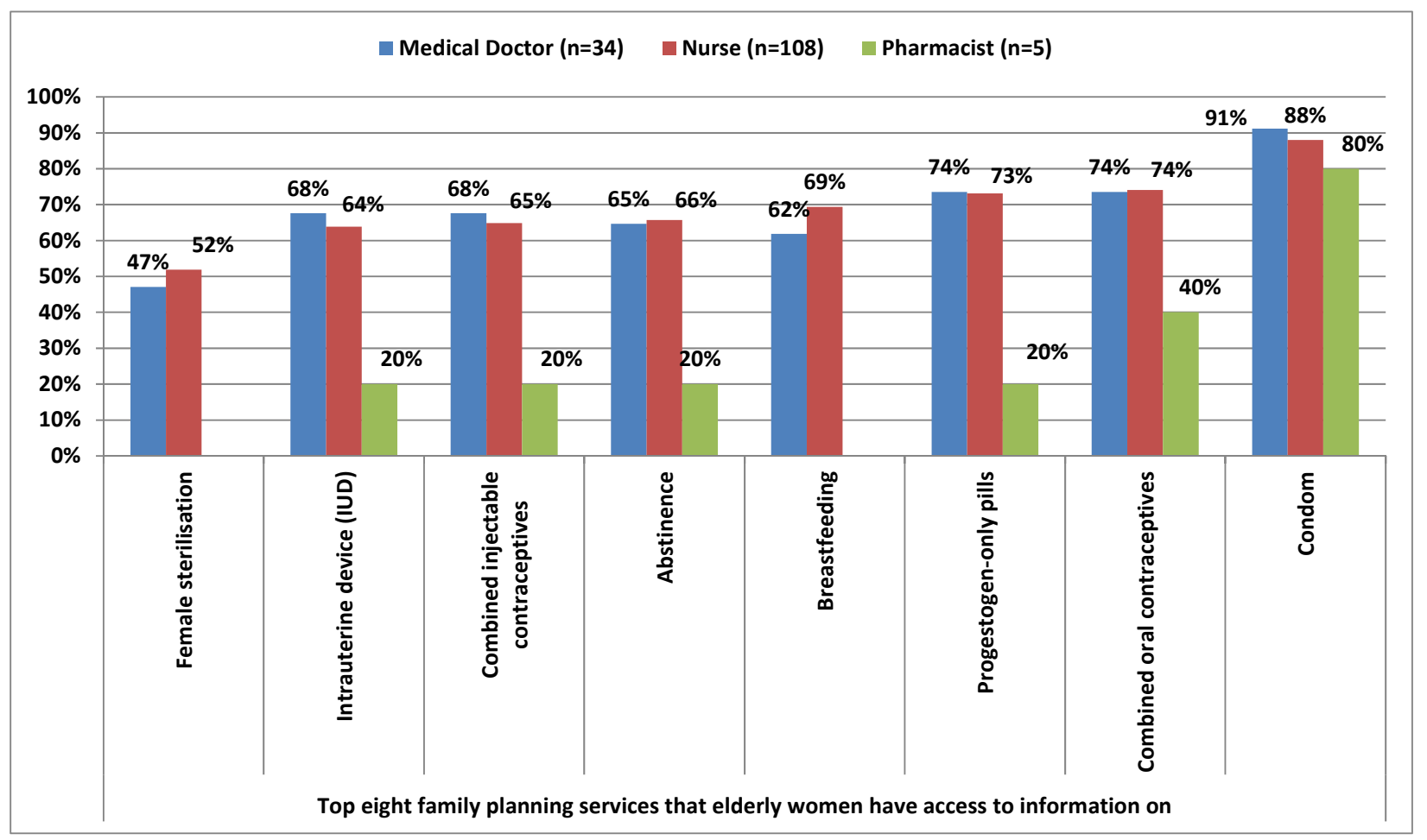

Figure 7. Top family planning services that elderly women have information on.

Table 2. Health providers' perception on SRH whose information is accessible to elderly women.

\begin{tabular}{|c|c|c|c|}
\hline \multirow[b]{2}{*}{ Information on SRH services available to elderly women } & \multirow[b]{2}{*}{ Medical doctor $(\mathrm{n}=36)$} & \multicolumn{2}{|c|}{ Employment status } \\
\hline & & Nurse $(n=113)$ & Pharmacist $(\mathrm{n}=3)$ \\
\hline Abortion (where legal) & $44 \%$ & $25 \%$ & $33 \%$ \\
\hline ALL SRH SERVICES & $25 \%$ & $34 \%$ & $33 \%$ \\
\hline Post abortion care & $47 \%$ & $51 \%$ & $0 \%$ \\
\hline Treatment of cervical cancer & $64 \%$ & $57 \%$ & $33 \%$ \\
\hline Services for victims of sexual violence & $56 \%$ & $65 \%$ & $33 \%$ \\
\hline Emergency obstetric care & $64 \%$ & $68 \%$ & $33 \%$ \\
\hline Safe delivery & $78 \%$ & $83 \%$ & $67 \%$ \\
\hline Supply of contraceptives & $86 \%$ & $86 \%$ & $100 \%$ \\
\hline Antenatal care & $83 \%$ & $90 \%$ & $67 \%$ \\
\hline Postnatal care & $83 \%$ & $90 \%$ & $67 \%$ \\
\hline Treatment of HIV/AIDS & $89 \%$ & $92 \%$ & $33 \%$ \\
\hline Family planning & $86 \%$ & $93 \%$ & $100 \%$ \\
\hline Screening for STI's & $92 \%$ & $94 \%$ & $33 \%$ \\
\hline Treatment of STI's & $94 \%$ & $93 \%$ & $67 \%$ \\
\hline Screening for cervical cancer & $92 \%$ & $96 \%$ & $33 \%$ \\
\hline Prevention of mother to child transmission of HIV & $89 \%$ & $97 \%$ & $33 \%$ \\
\hline Screening for HIV/AIDS & $94 \%$ & $99 \%$ & $33 \%$ \\
\hline
\end{tabular}


Figure 8 shows that nurses (50\%) and medical doctors (16\%) were the main sources through which the elderly women got information on SRH/FP services that were available in the health care system in Botswana. Other sources included radio/television and relatives.

Analysis of the differences in the opinions of the healthcare providers using analysis of variance showed that there were no significant differences in the percentages of respondents sharing a particular opinion ( $p>$ 0.05 ). A further analysis on the differences in the opinions of the doctors and nurses (Table 3) showed that on all the variables studied, there were no significant differences in their views $(p>0.05)$. The correlation coefficient between the doctors' and nurses' opinions were very high, showing very close association the the views of the doctors and nurses. The study further showed that the information on both the sexual and reproductive health including family planning services are mostly provided in the form of printed materials (82\%), during the elderly women's consultation with doctors (65\%), during separate sessions for the women (41\%) or sometimes during sessions for both men and women (40\%) (Figure 9). Dissemination of information through use of such informative sessions as drama, film shows (14\%) or separate sessions for men (16\%) rarely occur. The results have implications on interventions to reach elderly women on their SRH/FP needs using printed materials and information provided by medical doctors during consultations. The institution of education sessions for women is also recommended.

Table 3. Test of the difference in the opinions of the doctors and nurses on some variables studied.

\begin{tabular}{|c|c|c|c|c|c|}
\hline Opinion of doctors and nurses & d.f & $\begin{array}{c}\text { Difference in } \\
\text { proportion }\end{array}$ & p-value & Decision & $\begin{array}{l}\text { Correlation } \\
\text { coefficient, r }\end{array}$ \\
\hline Family planning services available & 16 & 0.0433 & 0.1179 & n.s & 0.8295 \\
\hline Family planning services accessible & 16 & 0.0163 & 0.2660 & n.s & 0.9197 \\
\hline SRH services accessible & 16 & 0.0336 & 0.0850 & n.s & 0.9313 \\
\hline Access to information & 16 & 0.0166 & 0.1988 & n.s & 0.9306 \\
\hline
\end{tabular}

n.s = not significant at $5 \%$ level of significance.

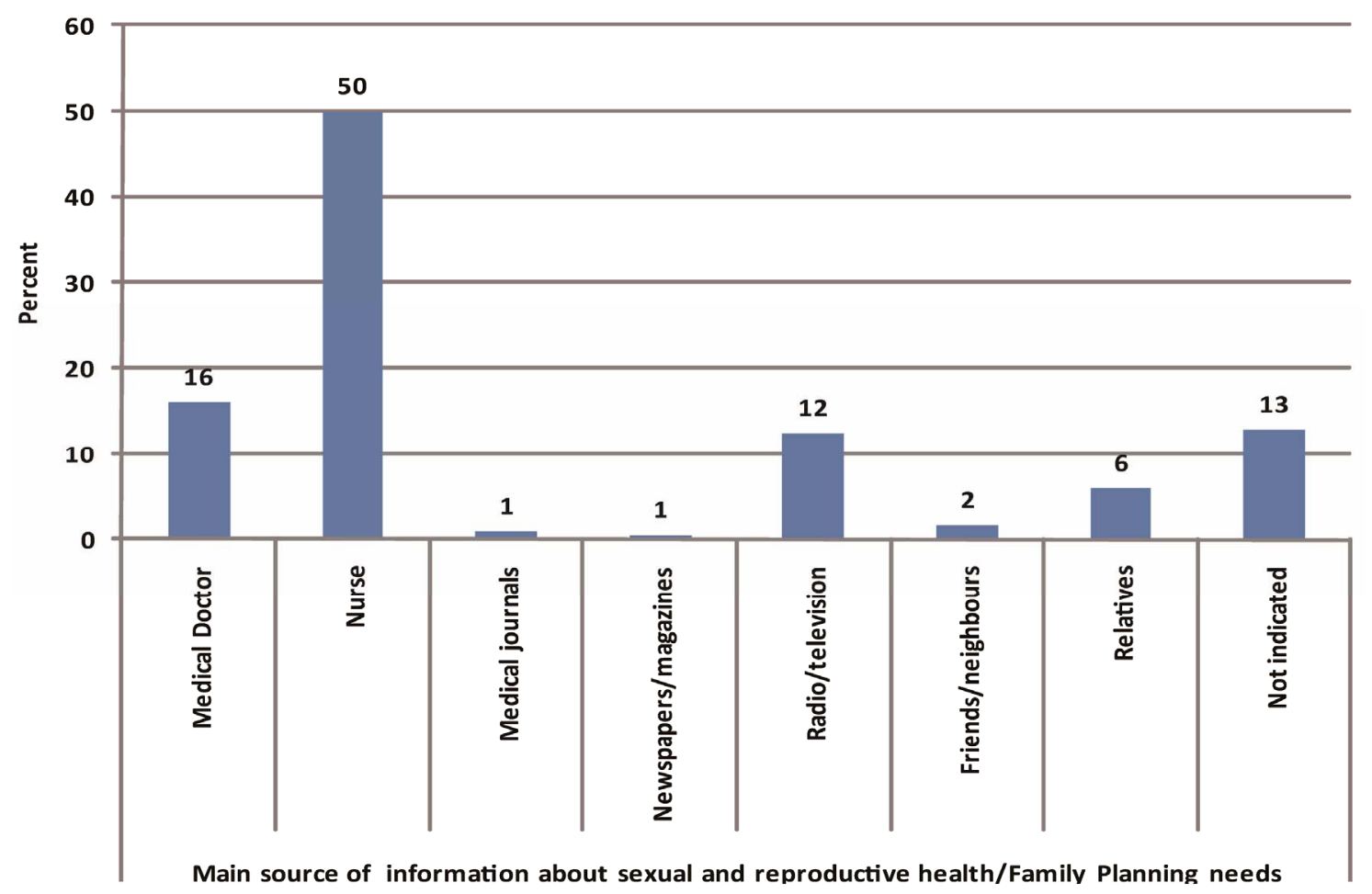

Figure 8. Main sources of information on SRH/FP services to the elderly women. 


\subsection{Identified Obstacles to Elderly Women Accessing Their SRH/FP Needs}

The key obstacles to the elderly women accessing their sexual and reproductive health needs including family planning identified by the healthcare providers are cultural diversity (80\%), people's sexual behavior and perceptions about sex (79\%), lack of knowledge about the desired SRH/FP services (76\%), religion (73\%) gender issues (62\%) and husband-wife relations/role (60\%) (Figure 10).

\subsection{Suggested Interventions to Mitigate the Obstacles to Accessing SRH/FP Needs and Policy Changes}

When asked, in an open-ended question, what measures could be adopted to improve the SRH/FP seeking behavior of the elderly women, the healthcare providers identified a number of such measures which include the top ten shown in Figure 11. An overwhelming majority of the healthcare providers (89\% and over) identified counseling (95\%), screening for breast cancer and treatment (95\%), routine screening for breast cancer (93\%), public awareness campaigns on the utility of family planning (92\%), production and circulation of appropriate education materials explaining the utility of SRH/FP care (92\%), effective training for healthcare providers and programme managers on how to meet the elderly women SRH/FP health seeking needs (92\%) as interventions to boost the elderly women's SRH/FP care (Figure 11).

On policy changes to be effected to improve access to $\mathrm{SRH} / \mathrm{FP}$ services by the elderly women, the healthcare providers recommended the establishment of separate clinic for the elderly women (22\%) and that separate clinics days be set aside to attend to the elderly women (9\%). Public awareness campaigns on SRH issues (15\%) need to be intensified and the number of service providers like doctors, nurses, and midwives be increased, while those on the ground should be trained (6\%) (Figure 12).

\section{Discussion}

This paper's main focus is to obtain the views of the healthcare providers (medical doctors, nurses and pharmacists) on how the sexual and reproductive health needs including family planning of the elderly women are met at the healthcare systems in the selected sites in Botswana. The study was cross-sectional and interviewed 169 healthcare providers (40 doctors, 123 nurses and 6 pharmacist) randomly selected from the four selected sites (Gaborone, Selibe Phikwe, Barolong and Kweneng East).

The study has shown, based on the opinions of all the pharmacists, $71 \%$ of the nurses and $67 \%$ of the doctors, that the healthcare system has no programmes that specifically target the sexual and reproductive health including family planning of this significant others and their SRH/FP needs are not met. It is well known that the elderly women have sexual and reproductive health problems which are carried over from the child-bearing ages [8-10]. The women are very relevant to the country as caregivers in their families in the current national HIV/AIDS programme and a substantial proportion of them are still sexually active. The authors, [18], have shown that $45 \%$ of the elderly women aged $50-59$, 31\% of those aged 60 - 69 years and $11 \%$ of those aged 70 79 years still enjoy sex with their partners, a result which is in line with $[6,7,24]$. It is important that a programme that targets the SRH/FP needs of the elderly women be put in place since their level of sexual activity could result in pregnancy.

The findings from the study revealed that availability of SRH/FP services in the healthcare system does not always translate into accessibility. Thus, although sexual and reproductive health services including family planning are very much available in the healthcare system, the elderly women are only able to access mostly condom, combined oral contraceptives, progestogen-only pills, combined injectable contraceptives, treatment for STIs, screening for HIV/AIDS, and screening for cervical cancer. The reasons given by the healthcare providers for the elderly women's inability to access SRH/FP services are cultural diversity (80\%), people's sexual behavior and perceptions about sex (79\%), lack of knowledge about the desired SRH/FP services (76\%), religion (73\%) and gender issues (62\%). These findings are in line with [25]. In the traditional Botswana society, sex and sexuality are mere social constructs. Both the family and societal norms are very much in place to socialize, regulate and control the sexual behavior of members. For instance, grandmothers start engaging in sexual conversations with girls from the age of 15 years while grandfathers do the same with boys. The discussions usually center on areas such as potential sex partners, sex and health issues, and preparation for sex in terms of what to expect from the male partner, how to handle the opposite sex partner, and when to say no to sex [26]. Culturally breastfeeding is done for two years and during this time the lactating mother is not supposed to engage in sex with the husband. If for some reason the woman is not able to breast-feed for two years then they both drink traditional medicine to prevent pregnancy. In this culture, women have no power when it comes to sexual decision matters. Not only that most men in this culture do not believe in using condoms, they say they develop rash around the male organs when they use condoms $[26,27]$. 


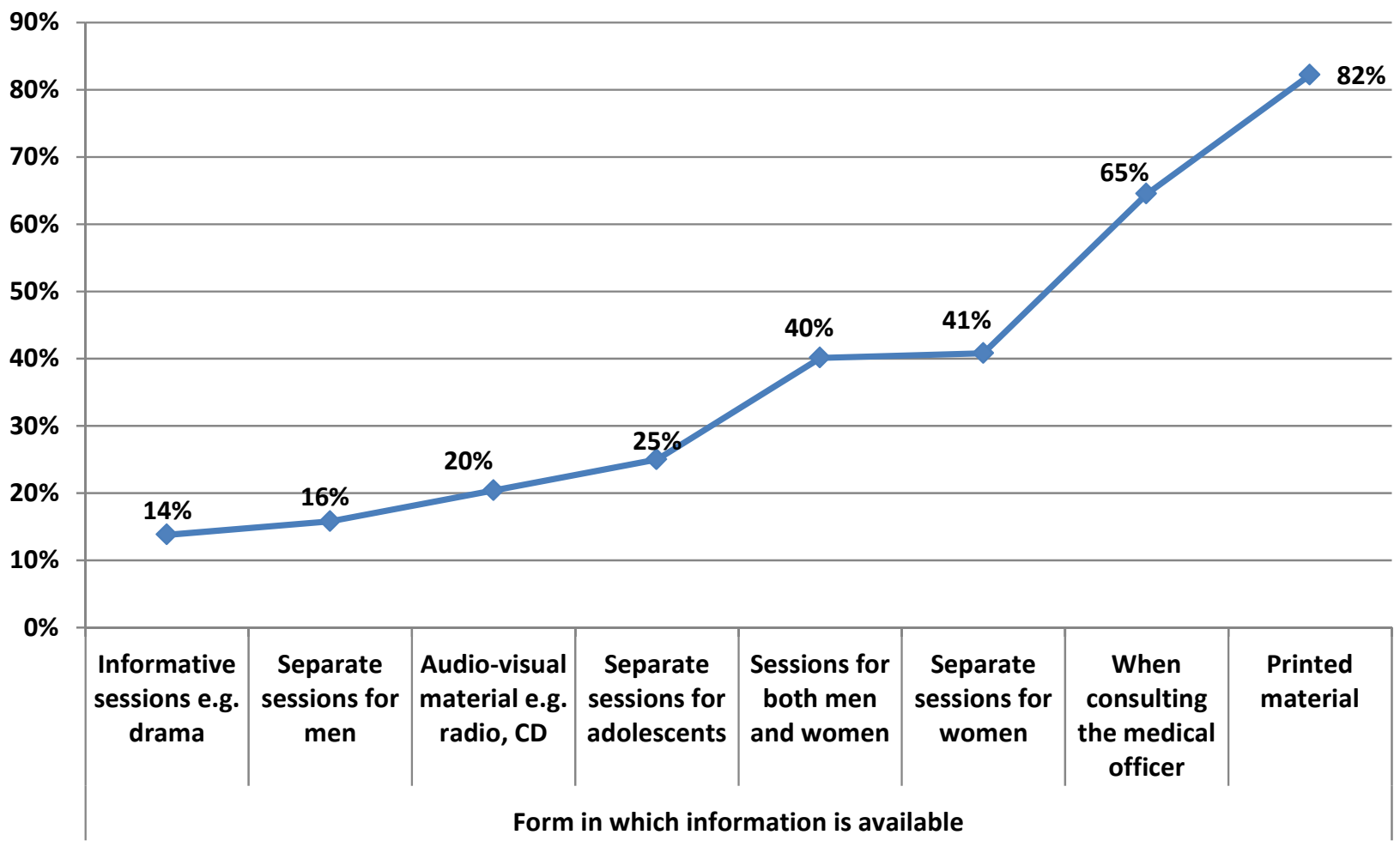

Figure 9. Form in which the information is made available.

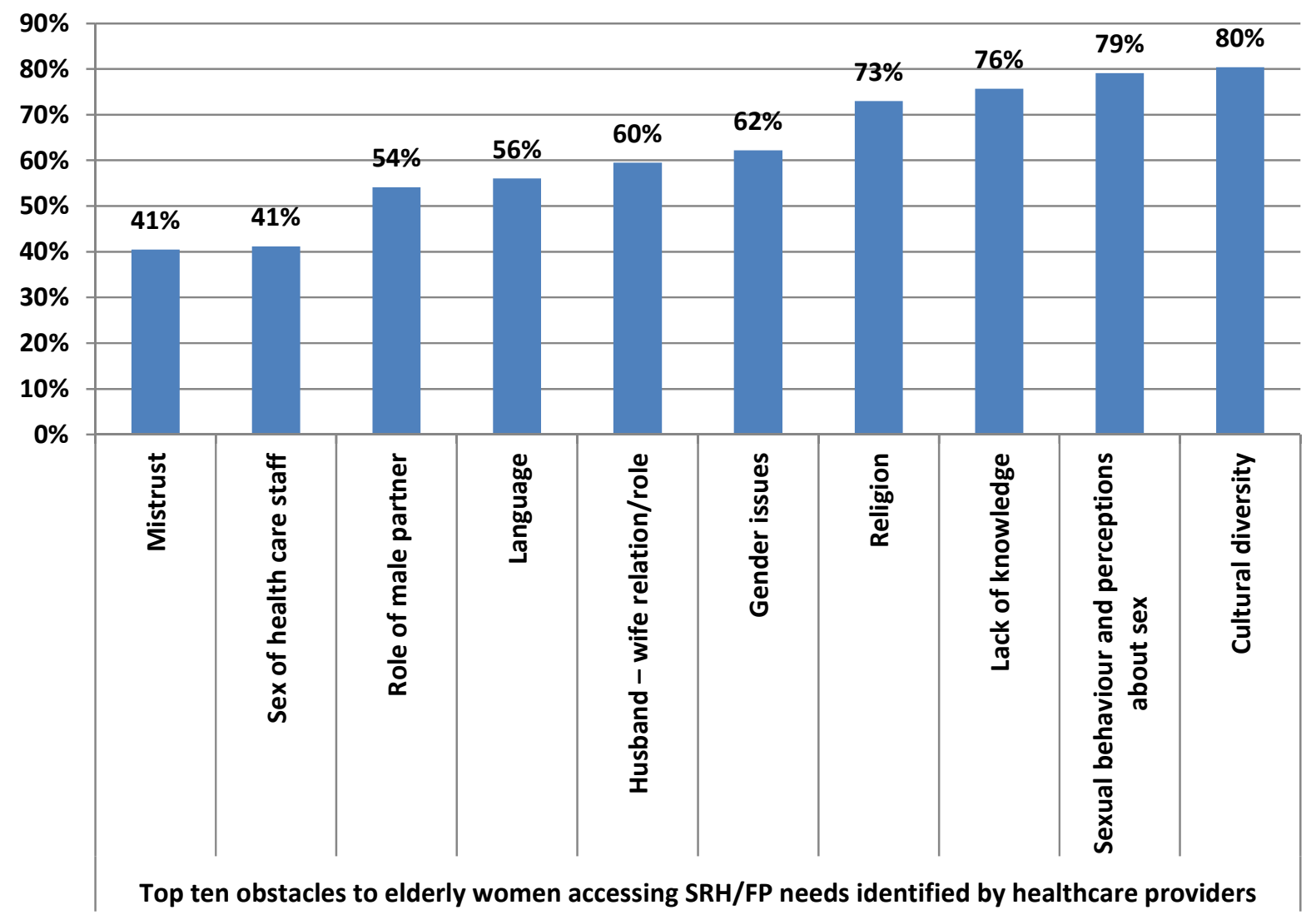

Figure 10. Identified obstacles by the health providers to the elderly women accessing SRH/FP. 

of Elderly Women from Selected Sites in Botswana

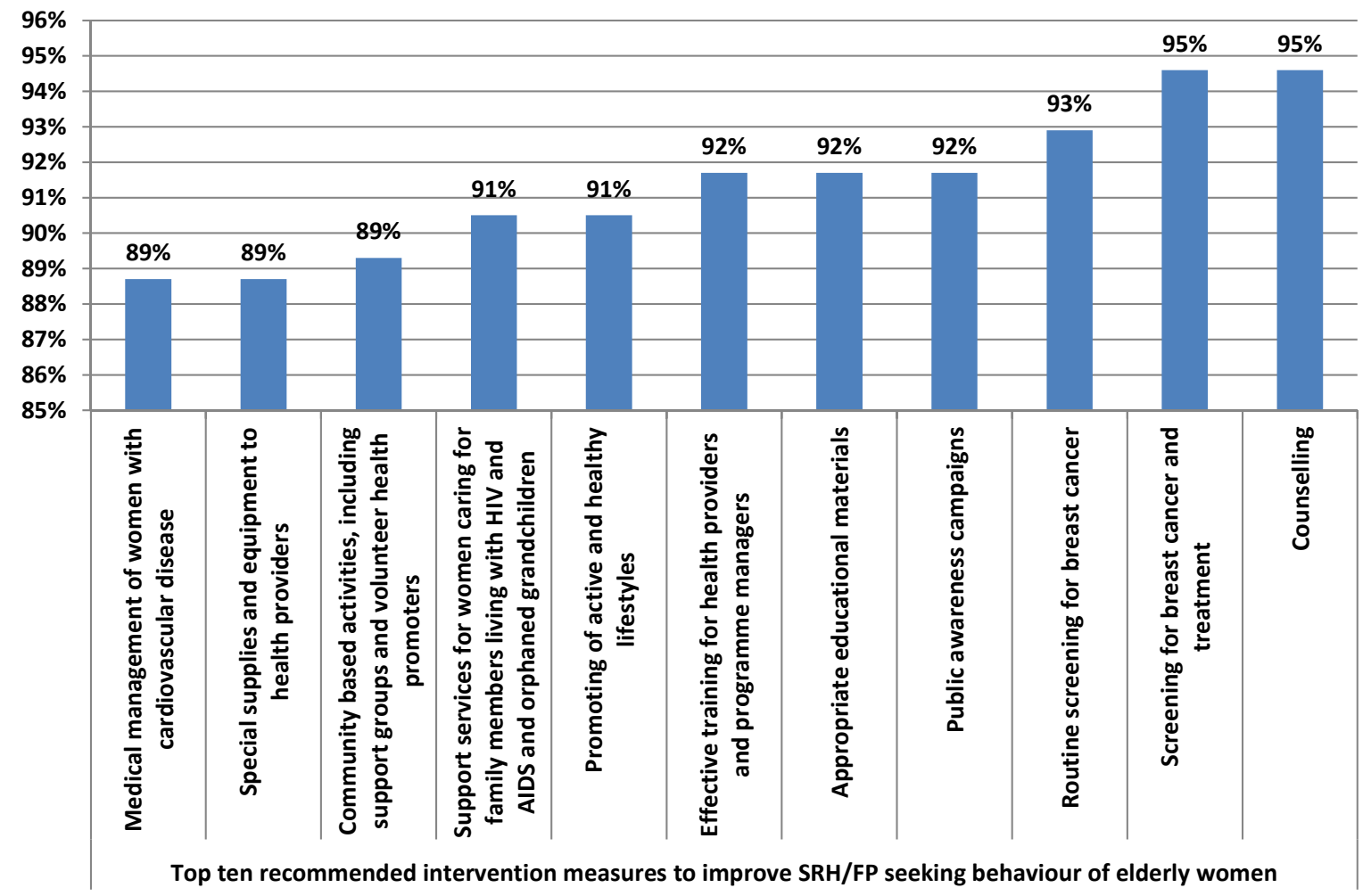

Figure 11. Top ten intervention measures identified by healthcare providers to improve SRH/FP.

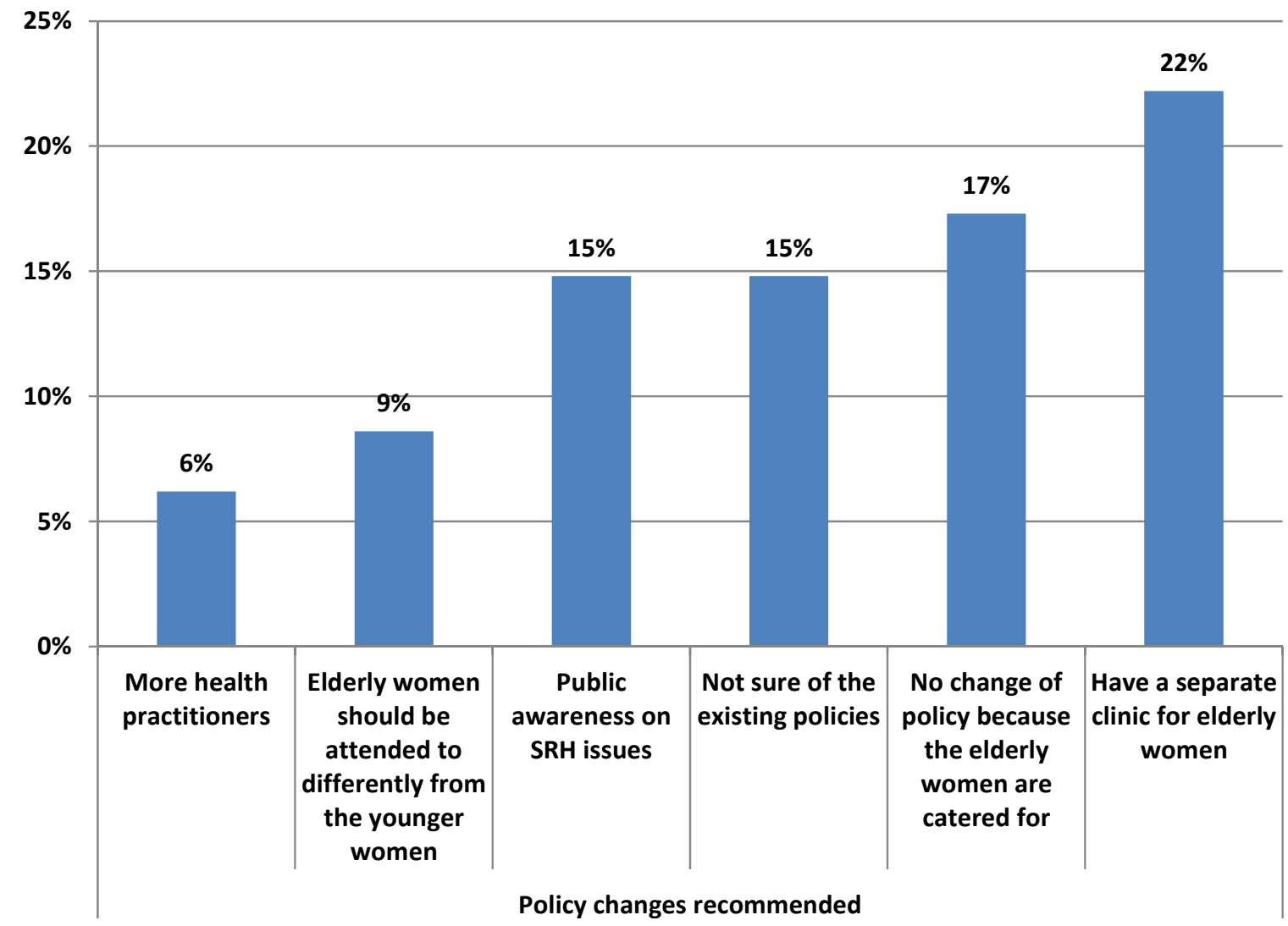

Figure 12. Recommended policy changes by the healthcare providers to improve the elderly women's SRH/FP access. 
There is the likelihood that the non-utilization of the SRH/FP services may have been influenced by the cultural environment of the elderly women thereby changing the perceptions and attitude of this cohort of elderly women towards sexual and reproductive health services including family planning.

Similar scenarios are found in the Nigerian society where sex and sexuality issues are taboos. As a result of perceived stigma and embarrassment, people are reluctant to discuss and address sexual health issues. As [28] puts it "Men are perceived as macho and women as passive. This gender role makes women and especially transgender people vulnerable in different ways to SRH problems, and inhibiting access to SRH services. For instance, men may associate masculinity with taking risks in their sexual relations which expose them to HIV and STIs, and may be reluctant or too embarrassed to seek out appropriate health information and care". When women are financially, materially or socially dependent on men, their ability to exercise control in relationships, such as negotiating the use of condoms during sex, determining when and how to have sex, become limited if not totally eroded. Social expectations about how women should behave sometimes place women in subordinate roles and increase their risk of being sexually assaulted, contracting STIs and having unwanted pregnancies, and also limit their access to SRH services [28].

Religion also plays a great role in access to SRH in Botswana as in many other countries. Certain religious faith have their reservation in the use contraception and use of condom and this affect access to family planning services.

Information is an important tool in influencing access to SRH services including family planning. A lot of people don't have access to information to know such a service exists in hospitals. Information needs to be shared on the availability of SRH services, so that prospective clients will access such services $[25,26,28]$. In the study, information on available SRH/FP services to be accessed by the elderly women was limited mostly to condom, combined oral contraceptives, progestogen-only pills, screening for HIV/AIDS, prevention of mother-to-child transmission (PMTCT), and screening for cervical cancer out of a lot many available services. This deprived information invariably delimits the choice of alternative SRH/FP services that the elderly women could use. In addition, the information existed mainly in printed materials, could be obtained during consultations with doctors or during separate sessions. For women of this age group who are mostly unemployed, with poor health conditions as most of them suffer from arthritis and the general body aches associated with ageing [18], accessing this information will be difficult. This view is further supported by the results of an earlier study on "Older Population and Health System: A profile of Botswana" which found out that women 50 years and over had difficulty in using the health services because the health facilities were far and transport was difficult to get [17]. There is need to address these obstacles to access if the elderly women are to visit the hospitals and clinics for their SRH/FP needs. Public awareness campaigns can help the healthcare system overcome some of these issues, while also promoting active and healthy lifestyles of the elderly women.

The healthcare providers, however, recommended as part of policy options to mitigate the obstacles to the elderly women accessing SRH/FP services, the following interventions: an expansion of counseling programmes, screening and treatment for breast cancer, public awareness campaigns, production and circulation of appropriate educational materials, effective training of healthcare providers and the establishment of separate clinic days for the elderly women' SRH/FP services. The healthcare providers need training that enables them to be better equipped to address the healthcare requirements of the elderly women. Such a training should result in attitudinal change so that they can value the elderly women and be able to educate the women on appropriate measures to take to improve the quality of their life as they age. Reproductive health programmes, which already served the women during their childbearing years, can be good for caring for women as they approach menopause and beyond. Healthcare providers can help ensure that the elderly women have access to appropriate contraceptive methods. Depending on available resources it might be necessary to include other services for elderly women such as counselling about menopause and its symptoms as well as information on how to maintain a healthy lifestyle through dieting and exercise [5]. The counseling services can be integrated into existing SRH/FP programmes. The Botswana Health Statistics Report (Health Statistics Reports, 1980-1998) shows an increasing trend in the incidence and prevalence of non-communicable diseases such as cancer, hypertension and diabetes, some of the diseases that the elderly women suffer from. Use of Community based activities, including support groups and volunteer health promoters, hold special promise since they can maximise the interest and resources of the elderly women themselves as well as the wider community. Retired nurses can be used for this purpose to cut down costs while ensuring efficient execution of the assignment. Mobile health services that will target the elderly can be strengthened as the elderly women may not be able to travel long distances.

\section{Acknowledgements}

The authors wish to thank the Office of Research and 
Development, University of Botswana for providing the fund for this study.

\section{REFERENCES}

[1] P. Kane, "Priorities for Reproductive Health: Assessing Need of Older Population in the Asia-Pacific Region," Medscape Women's Health, Vol. 6, No. 4, 2001. http://www.ncbi.nlm.nih.gov/pubmed/11547269

[2] K. Molesworth, "The Impact of Transport Provision on Direct and Proximate Determinants of Access to Health Services,” Swiss Tropical Institute, Basel, 2005.

[3] J. A. Ross and W. L. Winfred, "Unmet Need for Contraception in the Developing World and Former Soviet Union: An Updated Estimate," International Family Planning Perspectives, Vol. 28, No. 3, 2002, pp. 138-143. doi: $10.2307 / 3088256$

[4] J. Sherris and C. Herdman, "Preventing Cervical Cancer in Low-Resource Settings,” Outlook, Vol. 18, No. 1, 2001, pp. 1-8. www.path.org/files/eol18_1.pdf

[5] C. Elias, "Reproductive and Sexual Health of Older Women in Developing Countries," BMJ, Vol. 327, No. 7406, 2003, pp. 64-65. doi:10.1136/bmj.327.7406.64

[6] W. Marsiglio and D. Donnelly, "Sexual Relations Later in Life: A National Study of Married Persons," Journals of Gerontology, Vol. 46, No. 6, 1991, pp. S338-S344.

[7] Australian Bureau of Statistics, "Population Projections 1997 to 2051,” ABS, Canberra, 2002.

[8] WHO, "Information Needs for Research, Policy and Action on Ageing and Older Adults," Report of a Workshop on Creating a Minimum Data Set (MDS) for Research, Policy and Action on Ageing and the Aged in Africa, Harare, 20-22 January 2000.

[9] S. Jejeebhoy, M. Koenig and C. Elias, "Community Interaction in Studies of Gynaecological Morbidity: Experiences in Egypt, India and Uganda,” In: S. Jejeebhoy, M. Koenig and C. Elias, Eds., Reproductive Tract Infections and Other Gynaecological Disorders, Cambridge University Press, Cambridge, 2003. doi:10.1017/CBO9780511545627.008

[10] P. Senanayake, "Women and Reproductive Health in a Graying World," International Journal of Gynecology \& Obstetrics, Vol. 70, No. 1, 2000, pp. 59-67.

[11] M. M. Gelfand, “Sexuality among Older Women,” Journal of Women's Health and Gender-Based Medicine, Vol. 9, Suppl. 1, 2000, pp. s15-s20. doi:10.1089/152460900318812

[12] Ministry of Health Care and Nutrition, "Sri Lanka Demographic and Health Survey 2006/2007, Preliminary Report (Draft)," Department of Census and Statistics in Collaboration with Ministry of Health Care and Nutrition, 2008.

http://reliefweb.int/sites/reliefweb.int/files/resources/FBB C3A9800D95BC2C12574A60042860F-Full_Report.pdf

[13] A. Begum and H. T. Khan, "Obstetric Related Residual Morbidities among the Women in Bangladesh,” Journal of Prev Soc Medicine, Vol. 18, No. 1, 1999, pp. 22-29.
[14] Centre for Health and Gender Equity, "The Case for Comprehensive: Botswana-The Importance of Comprehensive, Rights-Based Approaches to Sexual and Reproductive Health,” Country Profile, 2012.

http://www.genderhealth.org/files/uploads/change/publica tions/botswanacasestudy.pdf

[15] World Bank, "GenderStats. Database of Gender Statistics. Summary Gender Profile,” 2008.

http://devdata.worldbank.org/genderstats/genderRpt.asp?r $\mathrm{pt}=$ profile\&cty=BWA, Botswana\& hm=home

[16] UNFPA, “Case Study: Botswana: Reproductive Health for Youth at the Workplace,” New York, TSD, 2003.

[17] The Non Communicable Disease Control Programme, “Older Population and Health System: A Profile of Botswana,” 2011.

http://www.who.int/ageing/projects/intra/phase_one/alc_i ntra1_cp_botswana.pdf

[18] N. O. Ama and E. Ngome, "Sexual and Reproductive Health of Elderly Women from Selected Sites in Botswana,” A Research Report Submitted to the Office of Research and Development, University of Botswana, Gaborone, 2012.

[19] Raosoft Incorporated, "Sample Size Calculator, 2004," 2011. http://www.raosoft.com/samplesize.html

[20] Statistics Botswana, "Botswana Statistical Year Book," Department of Printing and Publishing Services, Gaborone, 2004.

[21] T. Snijders, "Estimation on the Basis of Snowball Samples: How to Weight?” Bull Methodol Sociol, Vol. 36, 1992, pp. 59-70. doi:10.1177/075910639203600104

[22] D. Clifton, "Expanding Access to Family Planning," Population Reference Bureau,” 2012. www.prb.org/Articles/2010/expandfpaccess.aspx.

[23] S. Davies and World YWCA, "The Benefits of Investing in Family Planning: New Evidence and Regional Experiences," Presentation to Panel Discussion Sponsored by the Guttmacher Institute, New York, 2010.

[24] S. T. Lindau and N. Gavrilova, "Sex, Health, and Years of Sexually Active Life Gained Due to Good Health: Evidence from Two US Population Based Cross Sectional Surveys of Ageing,” BMJ, Vol. 340, 2010, Article ID: c810. doi:10.1136/bmj.c810

[25] J. Fowler, “Top Ten Barriers to Sexual and Reproductive Health Care in the Developing World," Pathfinder Field Journal, 2012. http://www.pathfind.org/site/PageServer?pagename=Fied

[26] P. G. Ntseane, “Cultural Dimensions of Sexuality: Empowerment Challenge for HIV/AIDS Prevention in Botswana," International Seminar/Workshop on Learning and Empowerment: Key Issues in strategies for HIV/AIDS Prevention, Chiangmai, 1-5 March 2004.

[27] P. G. Ntseane and J. Preece, "Why HIV/AIDS Prevention Strategies Fail in Botswana: Considering Discourses of Sexuality. Hepatitis, AIDS, Research Trust,” St. Florence, 2012.

http://www.heart-intl.net/HEART/061510/WhyHIV.htm

[28] Y. Adamu, "Nigeria Profile of the Sexual and Reproduc- 
tive Health Services Available at Primary Care Level,” United StatesDepartment of Defense HIV Program, Nigeria, 2012.
http://www.gfmer.ch/SRH-Course-2011/assignments/A2/ pdf/A2-005-Adamu-Yakubu.pdf 